\title{
RETOMAR 0 DEBATE SOBRE A REFORMA SANITÁRIA PARA AVANÇAR O SISTEMA ÚNICO DE SAÚDE (SUS)
}

\author{
Sônia Maria Fleury Teixeira \\ Professora da Escola Brasileira de Administração Pública e de Empresas, Fundação Getulio Vargas - RJ, Brasil
}

\section{INTRODUÇÃO}

Nos anos 1970, a partir dos trabalhos seminais de Arouca (publicado tardiamente em 2003) e Donnangelo (1976), uma profícua produção acadêmica inaugurou no Brasil o campo de conhecimento da Saúde Coletiva - intimamente ligado ao projeto da Reforma Sanitária Brasileira. Esse intenso debate ficou documentado nas teses acadêmicas, livros e artigos, sendo a Revista Saúde em Debate do Centro Brasileiro de Estudos de Saúde (Cebes) o principal veículo por onde circularam os autores e suas ideias. No entanto, as décadas de 1980 e em especial a de 1990 viram escassear essa produção, grandemente canalizada para a análise das vicissitudes da implantação do Sistema Único de Saúde e do processo de descentralização da política de saúde. Mesmo algumas publicações temporãs (como GERSCHMAN, 1995; GALLO, 1995; LOBATO, 1995) devem ser mais bem incluídas como parte dos trabalhos de pesquisa oriundos do NUPES - Núcleo de Estudos Políticos Sociais em Saúde da Escola Nacional de Saúde Pública, onde se tentou manter, até o final dos anos 1980, a tradição de se aliar a análise dos processos históricos e institucionais à produção de uma teoria da Reforma Sanitária, a qual permitisse a compreensão crítica e analítica dos primeiros e orientasse assim a práxis política.

Recentemente, duas publicações retomaram a linha de produção sobre a Reforma Sanitária, embora a primeira delas (FLEURY, BAHIA e AMARANTE, 2008) seja uma recopilação e organização dos artigos publicados até o número 23 da Revista Saúde em Debate, considerados pelos organizadores como os fundamentos da Reforma Sanitária, nos seguintes eixos: i) a construção do campo de conhecimento da saúde coletiva; ii) a construção da estratégia política; iii) teoria e tática da Reforma Sanitária. Já o livro de Paim (2008) é uma produção atual que se constrói na melhor tradição dos debates da Reforma Sanitária, avançando no plano histórico à luz de uma rigorosa compreensão teórica. O autor constata empiricamente o quase desaparecimento da temática da Reforma Sanitária na produção das teses acadêmicas nas décadas recentes e sua substituição seja pela análise do movimento sanitário e sua forma de participação institucional, seja pela análise da política de saúde. Por sua vez, Paim procura demonstrar que a Reforma Sanitária Brasileira (RSB) não é apenas o movimento social que a propulsou nem meramente uma política social e de saúde. Segundo o autor,

\footnotetext{
"parte-se da tese segundo a qual a RSB é constituinte de um projeto de reforma social (...) [sendo] o ângulo privilegiado de análise a própria reforma sanitária, enquanto ideia, proposta, projeto e processo, ainda que só analiticamente seja possível distingui-la do movimento, assim como o criador em relação à criação e à criatura..." (PAIM, 2008:32)
}

Essa compreensão, a qual compartilhamos, afasta-se dos estudos que reduzem a Reforma Sanitária a uma imagem objetiva de política social e à implantação institucional do SUS o que leva a vê-la como um projeto 
frustrado, inconcluso, desvirtuado. Compreender a dinâmica contraditória desse processo social de transformação representa a possibilidade de revisitar os conceitos e marcos teóricos que permitiram o avanço de um projeto de tal envergadura, mas que hoje carece de uma compreensão analítica que permita fazê-lo avançar criticamente.

Neste ensaio, formulamos nossas hipóteses analíticas sobre a concomitância nem sempre sinérgica entre os processos interiores da RSB, o que nos permite reafirmar a necessidade atual de reduzir algumas hipertrofias e visitar algumas áreas críticas, rompendo hiatos e continuidades que teimam em reduzir a RSB à institucionalização do SUS. Para desenvolver nosso raciocínio abordamos primeiramente o histórico da proteção social no Brasil para, a seguir, caracterizarmos a ruptura representada pela emergência do padrão constitucional de proteção social da Constituição Federal de 1988, no qual o projeto da RSB foi constituinte e constituído, tema amplamente discutido em todos os trabalhos que desenvolvemos nos últimos anos. No item sobre a Reforma Sanitária, retomamos as bases analíticas formuladas em sua origem, acrescidas agora da mencionada contribuição atual. Por fim, concluímos com nossa tese sobre os dilemas atuais entre o instituinte e o instituído, cuja superação é condição para o avanço da RSB.

\section{HISTÓRICO DA PROTEÇÃO SOCIAL}

As políticas sociais brasileiras desenvolveram-se, a partir do início do século passado, por um período de cerca de 80 anos, configurando um tipo de padrão de proteção social só alterado com a Constituição Federal de 1988. O sistema de proteção so- cial brasileiro, até o final da década de 1980, combinou um modelo de seguro social na área previdenciária, incluindo a atenção à saúde, com um modelo assistencial para a população sem vínculos trabalhistas formais. Ambos os sistemas foram organizados e consolidados entre as décadas de 1930 e 1940, como parte do processo mais geral de construção do estado moderno, intervencionista e centralizador, após a revolução de 1930. A construção do Estado nacional é um processo sempre inacabado, no qual vão sendo desenhadas as relações de poder na institucionalidade do aparato administrativo, seja ele voltado para a implantação do projeto econômico, seja ainda responsável pela reprodução da força de trabalho e incorporador das demandas políticas dos grupos subalternos.

A opção por um dado formato de política social, que se cristaliza na combinação de modelos distintos para diferentes segmentos dos trabalhadores, indica o lugar que cada um deles ocupa em uma dada correlação de forças, além das tendências internacionalmente preponderantes. Os diferentes modelos de proteção social são resumidos a seguir (FLEURY, 1994).

No modelo assistencial, as ações são de caráter emergencial, estão dirigidas aos grupos de pobres mais vulneráveis, e inspiram-se em uma perspectiva caritativa e reeducadora. Estas ações organizam-se com base na associação entre trabalho voluntário e políticas públicas, estruturam-se de forma pulverizada e descontínua, gerando organizações e programas muitas vezes superpostos. Embora permitam o acesso a certos bens e serviços, não configuram uma relação de direito social, tratando-se de medidas compensatórias que terminam por ser estigmatizantes. Por isso, denomino essa relação de cidadania invertida, na qual o indivíduo tem que provar que fracassou no mercado para ser objeto da proteção social.

No modelo de seguro social, a proteção social dos grupos ocupacionais estabelece uma relação de direito contratual, na qual os benefícios são condicionados às contribuições pretéritas e à afiliação dos indivíduos a tais categorias ocupacionais que são autorizadas a operar um seguro. A organização altamente fragmentada dos seguros expressa a concepção dos benefícios como privilégios diferenciados de cada categoria, como resultado de sua capacidade de pressão sobre o governo. Como os direitos sociais estão condicionados à inserção dos indivíduos na estrutura produtiva, Wanderley G. dos Santos (1979) denominou essa relação de cidadania regulada pela condição de trabalho.

No período da democracia populista (1946-1963), a expansão do modelo de seguro social vai fazer parte do jogo político de intercâmbio de benefícios por legitimação dos governantes, beneficiando de forma diferencial os grupos de trabalhadores com maior poder de barganha. Fenômeno este que ficou conhecido como massificação de privilégios e implicou o aprofundamento da crise financeira e de administração do sistema previdenciário.

A inflexão que vão sofrer os sistemas e mecanismos de proteção social a partir da instauração do regime burocrático-autoritário em 1964 obedeceu a quatro linhas mestras: a centralização e concentração do poder em mãos da tecnocracia, com a retirada dos trabalhadores do jogo político e da administração das políticas sociais; o aumento de cobertura, incorporando, precariamente, grupos anteriormente excluídos, como as empregadas domésticas, os trabalhadores rurais e os autônomos; a criação de fundos e 
contribuições sociais como mecanismo de autofinanciamento dos programas; a privatização dos serviços (em especial os sociais, como a educação universitária e secundária e a atenção hospitalar).

Nos meados da década de 1970, a luta pela democratização adquire novas características e estratégias. Antes confinada às universidades, aos partidos clandestinos e aos movimentos sociais, essa luta passa a ser localizada também no interior do próprio estado. Primeiramente, a partir das experiências inovadoras desenvolvidas pelas prefeituras oposicionistas eleitas em 1974; em segundo lugar, no interior dos órgãos centrais, responsáveis pelas políticas sociais, buscando aproveitar a crise financeira e o modelo das políticas sociais para introduzir elementos de transformação; em terceiro lugar, há um fortalecimento das capacidades técnicas dos partidos políticos e do parlamento, que passam a tomar a problemática social como parte de suas plataformas e projetos de construção de uma sociedade democrática.

O resgate da dívida social passa a ser um tema central da agenda da democracia, convergindo para ele movimentos de natureza diversa. Esse processo intensifica-se na década de 1980 através do surgimento de um rico tecido social emergente a partir da aglutinação do novo sindicalismo e dos movimentos reivindicatórios urbanos, da construção de uma frente partidária da oposição, e da organização de movimentos setoriais capazes de formular projetos de reorganização institucional, como o Movimento Sanitário.

Toda essa efervescência democrática foi canalizada para os trabalhos da Assembléia Nacional Constituinte, que se iniciaram em 1987. Em boa medida, a construção de uma ordem institucional democrática supunha um reordenamento das políticas so- ciais que respondesse às demandas da sociedade por maior inclusão social e equidade. Projetada para o sistema de políticas sociais como um todo, tal demanda por inclusão e redução das desigualdades adquiriu as concretas conotações de afirmação dos direitos sociais como parte da cidadania.

A Constituição Federal de 1988 representa uma profunda transformação no padrão de proteção social brasileiro, consolidando, na lei maior, as pressões que já se faziam sentir há mais de uma década. Inaugura-se um novo período, no qual o modelo da seguridade social passa a estruturar a organização e o formato da proteção social brasileira, em busca da universalização da cidadania. No modelo de seguridade social, busca-se romper com as noções de cobertura restrita a setores inseridos no mercado formal e afrouxar os vínculos entre contribuições e benefícios, gerando mecanismos mais solidários e redistributivos. Os benefícios passam a ser concedidos a partir das necessidades, com fundamentos nos princípios da justiça social, o que obriga a estender universalmente a cobertura e integrar as estruturas governamentais.

Essa Constituição avançou em relação às formulações legais anteriores, ao garantir um conjunto de direitos sociais, expressos no Capítulo da Ordem Social, inovando ao consagrar o modelo de Seguridade Social, como "um conjunto integrado de ações de iniciativa dos Poderes Públicos e da sociedade, destinadas a assegurar os direitos relativos à saúde, à previdência e à assistência social" (Título VIII, Capítulo II, Seção I, art. 194). A inclusão da previdência, da saúde e da assistência como partes da Seguridade Social introduz a noção de direitos sociais universais como parte da condição de cidadania, antes restritos à população beneficiária da previdência

$O$ novo padrão constitucional da política social tem uma perspectiva publicista, isto é, que se caracteriza pela universalidade da cobertura, pelo reconhecimento dos direitos sociais, pela afirmação do dever do Estado, pela subordinação das práticas privadas à regulação em função da relevância pública das ações e serviços nessas áreas e por um arranjo organizacional descentralizado.

A originalidade da Seguridade Social brasileira está dada em seu forte componente de reforma do Estado, ao redesenhar as relações entre os entes federativos e ao instituir formas concretas de participação e controle sociais, com mecanismos de articulação e pactuação entre os três níveis de governo. A organização dos sistemas de proteção social deveria assim adotar o formato de uma rede descentralizada, integrada, com comando político único e um fundo de financiamento em cada esfera governamental, regionalizada e hierarquizada, com instâncias deliberativas que garantissem a participação paritária da sociedade organizada, em cada esfera governamental.

\section{A REFORMA SANITÁRIA}

A Reforma Sanitária no Brasil é definida como uma estratégia política e um processo de transformação institucional cujo projeto e trajetória de institucionalização implicaram a reformulação de um campo de saber. Emergindo como parte da luta pela democracia, a Reforma Sanitária já ultrapassa três décadas, tendo alcançado a garantia constitucional do direito universal à saúde e a construção institucional do Sistema Único de Saúde (SUS).

A construção do projeto da Reforma Sanitária fundou-se na noção de crise: crise do conhecimento e da prática médica, crise do autoritarismo, crise do estado sanitário da população, crise do sistema de prestação de serviços de 
saúde (FLEURY, 1988). A constituição da Saúde Coletiva, como campo do saber e espaço da prática social, foi demarcada pela construção de uma problemática teórica fundada nas relações de determinação da saúde pela estrutura social, tendo como conceito articulador entre teoria e prática social, a organização da prática médica, capaz de orientar a análise conjuntural e a definição das estratégias setoriais de luta.

Partindo da análise dos processos de trabalho e do conceito-chave de organização social da prática médica, tal movimento opera uma leitura socializante da problemática evidenciada pela crise da medicina mercantilizada, bem como de sua ineficiência, enquanto possibilidade de organização de um sistema de saúde capaz de responder às demandas prevalecentes, organizado de forma democrática em sua gestão e administrado com base na racionalidade do planejamento (FLEURY, 1988, p. 196).

As decorrências dessa construção teórico-política apontam na direção da centralidade que a atuação junto ao Estado passaria a ter como campo privilegiado de intervenção e desenvolvimento das lutas políticas. No entanto, essa mesma concepção pode ser responsabilizada pela estruturação de um movimento social - o movimento sanitário - que se organiza em torno de uma proposta comum desde diferentes lugares, tais como a universidade, os sindicatos de profissionais de saúde, os movimentos populares, o Congresso Nacional.

A saúde passa então a ser vista como um objeto concreto e complexo, síntese de múltiplas determinações, cuja definição de Arouca (1982) compreende:

- campo de necessidades geradas pelo fenômeno saúde/enfermidade;

- produção dos serviços de saúde com sua base técnico-material, seus agentes e instituições organizados para satisfazer necessidades;

- espaço específico de circulação de mercadorias e de sua produção (empresas, equipamentos e medicamentos);

- espaço de densidade ideológica;

- espaço de hegemonia de classe, através das políticas sociais que têm que ver com a produção social;

- construção de uma potência tecnológica específica que permita solucionar problemas tanto individual como coletivamente.

A questão política que se coloca a partir dessa análise teórica é relativa às condições necessárias ao processo de politização e democratização da saúde. A relação entre democracia e saúde é proposta por Berlinguer (1979) ao postular que ambos são conceitos abstratos, e, mais que isto, orientações ético-normativas. Ainda que seja necessário reconhecer os conflitos de interesses e a oposição entre as forças conservadoras e as reformadoras, tanto no caso da democracia quanto no da saúde, tais conflitos não podem ser reduzidos a uma polarização classista. Por outro lado, do ponto de vista estratégico, a luta pela universalização da saúde aparece como parte intrínseca da luta pela democracia, assim como a institucionalização da democracia aparece como condição para garantia da saúde como direito de cidadania.

A estratégia expansionista de uma hegemonia em formação consubstancia-se na saúde através dos projetos da Reforma Sanitária, por meio dos quais se busca a concretização de:

- reconhecimento político e institucional do Movimento Sanitário como sujeito e dirigente do processo reformador;

- ampliação da consciência sanitária de forma a possibilitar o consenso ativo dos cidadãos (usuários e profissionais) em relação ao processo transformador no setor, bem como a natureza social das determinações que incidem sobre o processo saúde/doença e sobre a organização do cuidado médico;

- resgate da saúde como um bem de caráter público, embora contraditoriamente limitado pelos interesses gerados pela acumulação de capital. Por conseguinte, trata-se de expressar o caráter de bem público da saúde, consubstanciando-o na definição de uma norma legal e do aparato institucional que visam à garantia da sua universalização e equidade (FLEURY, 1992, p. 31).

Os fundamentos teóricos que permitem a construção da estratégia política da Reforma Sanitária foram baseados na compreensão de Gramsci do Estado integral, este entendido tanto o Estado como sociedade política, núcleo político administrativo e coercitivo, como também o Estado ampliado na luta pela hegemonia, o que envolve a disputa por significados e a construção de valores consensuais na sociedade civil. A compreensão do Estado integral pressupõe a luta pelo poder como uma transformação molecular e processual, a guerra de posições, que, sem ignorar os conflitos e a disputa por dominação, busca avançar na construção da hegemonia, ou direção intelectual e moral (BUCIGLUCKSMAN, 1980; COUTINHO, 1984). Para além de uma disputa que se dá no plano moral e cultural, a construção de hegemonia opera por meio de uma disputa institucional, tanto na sociedade civil como no seio do aparato material do Estado, onde se cristalizam as relações de poder, visto como uma arena estratégica de enfrentamento de projetos em conflito, segundo a concepção de Poulantzas (1977). Nesse sentido, o domínio dos instrumentos de gestão e a criação de novas formas de gestão 
que permitam a inovação e a alteração de poder no seio do aparato administrativo estatal tornam-se estratégicos.

Paim (2008) cita Heller (1986, p. 167) ao fazer a distinção entre reforma geral e reformas parciais. Enquanto a primeira propõe a transformação de toda a sociedade mediante reformas parciais, estas últimas, desconectadas de um projeto de reforma geral, tendem a converter-se em veículo de manipulação, pois criam a aparência de transformação de uma ordem social, mas ficam restritas a reformas das particulares e parciais instituições concretas. Para o mencionado autor, o projeto da RSB, ao propor a transformação da ordem social desde a saúde, insere-se na categoria de reforma geral, ainda que sua realização seja fruto de uma relação de forças que a caracterizou como um processo de transformismo institucional, tendo como desfecho uma reforma parcial.

Para compreender o processo da Reforma Sanitária foram levantadas as seguintes hipóteses explicativas (FLEURY,1990):

- a adoção de uma concepção ampliada de saúde como resultante das formas de organização social da produção, mas também fruto das lutas populares cotidianas, ambas atuando na conformação de sua concretização histórica e singular;

- a democracia é o processo de reconhecimento dos trabalhadores como sujeito político a partir de suas lutas, em um processo mútuo de reconhecimento (auto e hetero) identidades sociopolíticas entre diferentes sujeitos;

- a incorporação das demandas sanitárias por meio de um conjunto de dispositivos legais e institucionais, configurando distintas cidadanias, é, ao mesmo tempo, resultante da correlação de forças existentes e elemento ativo na conformação de identidades políticas e sociais;
- as Reformas Sanitárias quase sempre emergem em um contexto de democratização e estão associadas à emergência das classes populares como sujeitos políticos, geralmente em aliança com setores da classe média;

- são elementos desse processo reformador: a generalização da consciência sanitária; a construção de um paradigma analítico fundado na determinação social da saúde e da organização das práticas; o desenvolvimento de uma nova ética profissional; a construção de um arco de alianças políticas em torno da defesa do direito à saúde; a criação de instrumentos de gestão democrática e controle social do sistema de saúde;

- o caráter político da Reforma Sanitária será dado pela natureza das transições democráticas experimentadas em cada contexto nacional, sejam elas transições pactuadas ou transições por colapso do autoritarismo;

- o formato e o conteúdo político da reforma provirão da confluência de pelo menos alguns fatores, tais como: o caráter político-ideológico da coalizão que impulsiona o processo de democratização e seus embates com a coalizão conservadora; a articulação do processo da Reforma Sanitária com as estratégias de transição à democracia; o timing da Reforma em relação ao processo de democratização; a capacidade de alterar a cultura política prevalecente em direção à universalização dos direitos e a garantia de práticas administrativas participativas;

- a sustentabilidade do processo de reforma dependerá da capacidade de promover mudanças efetivas no nível do controle institucional, da qualidade dos serviços e da eficácia das ações e serviços, o que garantirá a preservação do apoio social à reforma;
- a sustentabilidade do processo reformador dependerá da redução das restrições financeiras e de ordem política à construção de um sistema amplo de proteção social; da capacidade de transacionar os conflitos gerados pelo próprio processo reformador; da permeabilidade da burocracia e dos profissionais de saúde às mudanças;

- as perspectivas da Reforma Sanitária derivam da capacidade apresentada pela coalizão reformadora de imprimir mudanças efetivas $e$ no tempo justo sobre as estruturas institucionais de forma a evitar que o Estado filtre os aspectos racionalizadores da proposta e mine sua base política.

Em síntese, a Reforma Sanitária brasileira tomou como ponto de partida o caráter dual da saúde, entendido como a possibilidade de ser tomada, ao mesmo tempo, como valor universal e núcleo subversivo da estrutura social. Como valor universal, torna-se um campo especialmente privilegiado para a construção de alianças suprapartidárias e policlassistas. Como núcleo permanentemente subversivo da estrutura social, indica uma possibilidade sempre inacabada em um processo de construção social de uma utopia democrática.

\section{REFORMA SANITÁRIA E SISTEMA ÚNICO DE SAÚDE - DILEMAS ENTRE 0 INSTITUINTE E 0 INSTITUÍDO}

O movimento que impulsionou a Reforma Sanitária brasileira colocou como projeto a construção contrahegemônica de um novo patamar civilizatório, o que implica uma profunda mudança cultural, política e institucional capaz de viabilizar a saúde como um bem público. 
Os princípios que orientaram esse processo foram:

- um princípio ético-normativo que insere a saúde como parte dos direitos humanos;

- um princípio científico que: compreende a determinação social do processo saúde/doença;

- um princípio político que assume a saúde como direito universal inerente à cidadania em uma sociedade democrática;

- um princípio sanitário que entende a proteção à saúde de forma integral, desde a promoção, passando pela ação curativa, até a reabilitação.

No entanto, a construção do Sistema Único de Saúde, aprovado na Constituição Federal de 1988, ocorreu em um contexto em que a disputa ideológica favoreceu amplamente o projeto neoliberal, reorganizando as relações entre Estado e sociedade em bases distintas daquelas pressupostas por seus formuladores.

Foram retomadas as orientações liberais que propugnam por uma forte redução da presença do Estado, seja na economia seja nas políticas sociais. Para tanto, utilizaram-se instrumentos como a privatização das empresas estatais e mesmo de serviços sociais, a redução da pauta e/ou valor dos benefícios sociais juntamente com o aumento das dificuldades para alcançá-los, a introdução de mecanismos da economia de mercado como a competição gerenciada na organização dos serviços sociais, a redução do papel de provedor do Estado com a transferência dessa competência a organizações civis lucrativas ou não.

Ainda com relação ao aparato estatal, houve uma desmontagem das carreiras profissionais e dos núcleos produtores de conhecimento e estratégias ligados ao projeto de desenvolvimento nacional, vistos como comprometidos com a lógica, seja populista, seja intervencionista, do modelo econômico anterior, visto como responsável pela crise fiscal do Estado.

O predomínio da lógica de acumulação do capital financeiro teve como consequência para as economias endividadas dos países menos desenvolvidos sua inserção como exportadores líquidos de capital por meio do pagamento dos juros sobre a dívida pública. A política pública passou a ter como objetivo central a estabilização monetária, mesmo quando isto implicou o abandono do crescimento econômico como consequência de uma política de juros que promoveu uma absurda transferência de recursos desde a área produtiva para o Estado, por meio do aumento da carga tributária e desde o Estado para o capital financeiro, por meio do pagamento dos juros sobre a dívida e os títulos públicos.

No âmbito cultural e social, houve uma transformação que acentuou valores como o individualismo e o consumismo, com as elites e setores das altas capas médias orientadas cada vez mais para um padrão norteamericano de sociedade de consumo, em detrimento de valores como a solidariedade, a igualdade e a participação cívica. O divórcio entre uma classe média alienada da realidade nacional e a população marginalizada da globalização reflete-se, na saúde, na existência de um sistema de seguros privados e um sistema público para os mais pobres, mas ao qual os assegurados recorrem em várias situações.

O esgarçamento de um tecido social que começara a aflorar em décadas anteriores, com a forte presença dos movimentos sociais e a negação das expectativas solidificadas com a transição à democracia, vai ter como consequência a ausência de mecanismos de integração social, seja por meio de um mercado de trabalho que cada vez é mais informal, seja por políticas de proteção social que não alcançam combater a exclusão e a desigualdade, que marginalizam setores populacionais em situação de alta periculosidade e vulnerabilidades crescentes nas grandes cidades. $\mathrm{O}$ aumento e a banalização da violência passam a ser o cotidiano das grandes cidades, revelando, paradoxalmente, a incapacidade da democracia eleitoral de gerar mecanismos de coesão social.

$\mathrm{Na}$ área de políticas sociais, há uma substituição do modelo corporativo, de acesso limitado e fragmentado por setores ocupacionais, por um novo modelo que se baseia na individualização do risco. Para aqueles que podem pagar por seus riscos sociais, há uma explosão da oferta de seguros sociais em áreas como a saúde e as aposentadorias. Essa expansão do mercado ocorre seja com a anuência e promoção do Estado por meio de subsídios e renúncias fiscais, seja com a ausência de uma regulamentação efetiva que possa conter os abusos e desrespeitos aos direitos dos consumidores. Só depois de fortalecido esse mercado, seria promovida sua regulamentação, ainda recente e precária, permitindo que os portadores de seguros sejam também usuários do SUS, que termina funcionando como um tipo de resseguro para alguns tratamentos.

Para a população mais pobre o princípio da individualização dos riscos vai se concretizar em programas de proteção focalizados, cujos benefícios em serviços ou transferências de renda implicam requerimentos de provas de necessidade e cumprimento de certas condicionalidades impostas aos beneficiários. Dessa forma, a política social passa a funcionar como mecanismos simultâneos de promoção e controle social, desvinculados da condição de exercício de um direito social.

Na luta ideológica pela construção da saúde como um valor público há 
um retrocesso importante, no qual a saúde passa a ser vista como um bem de consumo e, mais do que isto, como um modelo de consumo caracterizado pela ausência da dor e do sofrimento, a busca inesgotável do prazer e da construção no próprio corpo de um padrão estético de beleza a ser atingido por meio de sucessivas intervenções (das tatuagens às cirurgias plásticas, passando pelas vitaminas e anabolizantes).

Novamente, trata-se de um modelo social que prescinde de laços sociais, em que o outro se torna objeto e não é um sujeito que deva ser mais que tolerado, reconhecido como igual, ainda que diverso, em um processo de comunicação na esfera pública.

Este contexto no qual o movimento da Reforma Sanitária constrói a sua institucionalidade é pois altamente desfavorável à implementação de políticas públicas universalistas e cheio de dilemas e contradições a serem enfrentados. No entanto, a reforma sanitária prossegue e seu curso pode ser mais bem identificado a partir dos seus processos constitutivos.

A construção do projeto da reforma se dão por meio de três processos que, embora simultâneos, têm compassos distintos e tais descompassos geram novas tensões e algumas complementaridades. São eles os processos de subjetivação, de constitucionalização e de institucionalização. A subjetivação diz respeito à construção de sujeitos políticos, a constitucionalização trata da garantia de direitos sociais e a institucionalização trata do aparato institucional - incluindo os saberes e práticas - que garante a implantação das políticas de saúde.

Touraine (1966, p. 23) designa por sujeito

\footnotetext{
"a construção do indivíduo (ou grupo) como ator, através da associação de sua liberdade afirmada com sua
}

experiência de vida assumida e reinterpretada. O sujeito é o esforço de transformação de uma situação vivida em ação livre; introduz a liberdade no que aparece, em primeiro lugar, como determinantes sociais e herança cultural".

Ainda afirma que

"Um indivíduo é um sujeito se, em
suas condutas, consegue associar o
desejo de liberdade com a filiação a
uma cultura e o apelo à razão; por-
tanto, um princípio de individuali-
dade, um princípio de particularis-
mo e um princípio universalista"
(TOURAINE, 1966, p. 28).

Nesse sentido, a primeira etapa de luta pela democracia foi também aquela em que predominou a construção de sujeitos políticos capazes de formular e conduzir o processo da Reforma Sanitária. Se nessa fase os atores políticos assumem um caráter de movimento social - o movimento sanitário em suas várias expressões - à medida que a institucionalização e a constitucionalização ocorrem, novos sujeitos emergem na cena política e passam mesmo a ter nela o predomínio.

Em outras palavras, o êxito da reforma como fruto das lutas desse ator político, movimento sanitário, vai gerar, contraditoriamente, a superação desse caráter de movimento vindo da sociedade civil como crítica ao Estado, em direção a atores políticos que são parte da institucionalidade estatal, tais como os secretários municipais e estaduais de saúde, os promotores públicos, a burocracia reformadora.

Se a hipertrofia da subjetivação pode representar uma tendência seja à individualização anômica, seja ao "basismo", a hipertrofia da constitucionalização tem como consequência a judicialização da política e a hipertrofia da institucionalização implica a burocratização dos processos sociais (a respeito de hipertrofias, ver SANTOS, 1994).

$\mathrm{Na}$ fase intermediária da reforma, houve uma crescente normalização do processo de descentralização, com um emaranhado de normas operacionais e mecanismos de repasses de recursos financeiros que terminaram por assegurar à burocracia central a preservação de poder, mesmo que isto tenha implicado o arrefecimento da política.

No entanto, o fortalecimento de atores políticos institucionais, como os secretários de saúde, gerou tensões crescentes no exercício do poder compartilhado, acarretando conflitos que foram trabalhados a partir das esferas de pactuação que haviam sido institucionalizadas, tendo gerado, no momento atual, o Pacto da Saúde, que inclui os importantes Pacto pela Vida e Pacto de Gestão (MINISTÉRIO DA SAÚDE, 2006).

A desigual distribuição de recursos e poder entre os atores tende, todavia, a favorecer sempre os grupos de gestores e os grupos corporativos, impedindo que os ideais da reforma se concretizem e garantam a centralidade do usuário cidadão.

Este é o maior desafio da fase atual da reforma, que implica não apenas a garantia do acesso dos usuários, mas a reorientação das lógicas burocrática e profissional, que atualmente organizam o sistema, em direção a outra lógica que, por ter o usuário como central ao sistema de saúde, garante seus direitos desde a humanização do acolhimento até a eficácia e resolutibilidade do cuidado.

Finalmente, caracteriza também a fase atual de implantação do SUS a presença marcante dos atores jurídicos e até mesmo o desenvolvimento de um ramo do direito que ficou conhecido como direito sanitário. Esta é uma consequência da constitucionalização do direito à saúde. No entanto, como 
a justiça tende a entender o direito à saúde como um direito individual e não como direito coletivo, ela age em função daqueles pacientes que, por possuírem maior informação e maiores recursos, são capazes de acioná-la quando têm seus direitos negados. Ao atender a essas demandas individuais, a justiça impede o planejamento das ações de saúde e, muitas vezes, canaliza os escassos recursos para procedimentos individuais em detrimento de ações coletivas.

Nesse sentido, é preciso retomar a perspectiva de difusão da consciência sanitária, como consciência política do direito à saúde, já que está provado que não se cria a igualdade por decreto, somente por meio da lei.

Com relação à institucionalização, o SUS operou uma reforma democrática do Estado que, mesmo tendo enfrentado todas as pressões dos governos que adotaram um modelo de reforma distinto e que pressupunha o esvaziamento da função estatal de provedor, conseguiu não apenas se manter, como também servir de modelo para a reorganização de sistemas de gestão compartilhada em outras áreas (como a assistência social e a segurança pública).

O modelo de reforma do Estado embutido na institucionalização do SUS foi sustentável tanto por ter conseguido manter uma coalizão reformadora orgânica e atuante, como por fazer o processo avançar com base na legislação existente, ou seja, no que ficou conhecido como "o desafio de fazer cumprir a lei”. Nesse sentido, subjetivação, institucionalização e constitucionalização funcionaram de maneira sinérgica e complementar.

O SUS pode ser visto como um modelo de republicanismo cívico por sua capacidade, juntamente a outros esforços, de permitir o revigoramento das instituições republicanas, seja no fortalecimento do Legislativo, com a atuação cada vez mais qualificada da Comissão da Seguridade Social e da Família e com ação suprapartidária da Frente Parlamentar da Saúde, seja na Justiça, ao desenvolver o direito sanitário ou ainda com a organização dos procuradores públicos que atuam na saúde (através da AMPASA), seja no Executivo, ao introduzir um modelo de cogestão e de redes de políticas.

O SUS reorganizou o Executivo através dos seguintes instrumentos e processos:

- mecanismos de participação e controle social representados pelos Conselhos de Saúde, existentes em cada uma das esferas governamentais, com representação paritária de membros do Estado e de membros da sociedade civil. Os Conselhos, para além de instrumentos de controle social, externos ao aparelho de Estado, devem ser entendidos como "componentes do aparelho estatal, onde funcionam como engrenagens institucionais com vigência e efeitos sobre os sistemas de filtros, capazes de operar alterações nos padrões de seletividade das demandas" (CARVALHO, 1997, p. 99);

- mecanismos de formação da vontade política, as Conferências de Saúde, realizadas periodicamente, em todos os níveis do sistema, que, em uma interação comunicativa e deliberativa, coloca todos os atores sociais em interação em uma esfera pública de comunicação, periodicamente convocada. Além de mecanismos de aprendizagem e reconhecimento social, essa instância fortalece a sociedade organizada que participa do processo de construção dos lineamentos políticos mais amplos do sistema, embora sem caráter vinculativo;

- mecanismo de gestão compartilhada, negociação e pactuação entre os entes governamentais envolvidos em um sistema descentralizado de saúde. A suposição de interesses distintos e de câmaras institucionais de negociação dessas diferenças e de geração de pactos de gestão é uma das grandes inovações desse modelo federativo inovador que assume a diferenciação como realidade e a igualdade como princípio político e meta institucional.

Um federalismo diferenciado pelas desigualdades sociais e regionais existentes na sociedade brasileira, mas igualado pela criação de mecanismos de descentralização, pactuação e participação que geram novas capacidades e poderes locais.

A criação do SUS e sua revisão periódica, de forma a enfrentar as diferenças internas e as ameaças constantes representadas pela ausência de recursos financeiros necessários e pela crescente presença do mercado de seguros, tem sido um desafio constante. Ainda que se possa dizer que com isto se tenha alcançado o objetivo de construir um valor público, de tal forma que a política de saúde seja hoje mais uma questão de Estado do que de governos, certo é que a incapacidade de transformar as práticas cotidianas que desqualificam o usuário e o destituem dos direitos humanos ao acolhimento digno e a atenção eficaz segue sendo um desafio para a democratização da saúde.

A incapacidade de implantar um modelo integral de atenção à saúde, de reversão da predominância do modelo curativo para um modelo preventivo, a incapacidade de as melhorias na gestão do sistema gerar melhorias correspondentes na gestão das unidades, a falta de uma renovação ética nos profissionais do sistema de saúde, a dependência de insumos e medicamentos cujos preços e condições de produção por grandes empresas multinacionais fogem ao con- 
trole dos Estados nacionais, e muitos outros mais, são desafios presentes no momento atual da Reforma Sanitária.

No entanto, a ênfase atual nos aspectos legais e institucionais termina por deixar de lado a necessidade de retomar, permanentemente, o caminho da construção dos sujeitos políticos da reforma. A formação de identidades, a difusão da consciência sanitária, a organização em coalizões sociais em defesa de uma reforma radical são as únicas maneiras de superar os entraves atuais e aprofundar a democratização da saúde. A subversão continua sendo poder pensar que a democratização da saúde é uma utopia para a qual, hoje mais do que nunca, temos condições de construir e assim transformar o Estado e a sociedade brasileira.

\section{REFERÊNCIAS}

AROUCA, A. S. O dilema preventivista: contribuição para a compreensão e crítica da medicina preventiva. Rio de Janeiro. Fiocruz, 2003.

AROUCA, A. S. Salud en la transición. II Seminário Latinamericano de Medicina Social. Manágua, 1982.

BERLINGUER, G. Democracia y salud. IV Congreso Latinoamericano y V Congreso Mundial de Medicina Social. Medellín, 1987.
BUCI-GLUCKSMAN, C. Gramsci e o estado. São Paulo: Paz e Terra, 1980.

CARVALHO, A. I. Conselhos de saúde, responsabilidade pública e cidadania: a reforma sanitária como reforma do estado. In: FLEURY, S. Saúde e democracia: a luta do CEBES. São Paulo: Lemos, 1997.

COUTINHO, C. N. A dualidade de poderes. São Paulo: Brasiliense, 1984

DONANGELO, M. C. F. Saúde e sociedade. São Paulo: Duas Cidades, 1976.

ESCOREL, S. Reviravolta da saúde: origens e articulação do movimento sanitário. Rio de Janeiro: Fiocruz, 2005.

FLEURY, S. Estados sem cidadãos. Rio de Janeiro: Fiocruz, 1994.

FLEURY, S. A questão democrática na saúde. In: FLEURY, S. Saúde e democracia: a luta do CEBES São Paulo: Lemos, 1997.

FLEURY, S. La reforma sanitaria: en busca de una teoría. Guadalajara: Editorial Universidad de Guadalajara, 1990.

FLEURY, S. Saúde: coletiva? Questionando a onipotência do social. Rio de Janeiro: Relume Dumará, 1992

FLEURY, S. A reforma sanitária brasileira. In: BERLINGUER, G; TEIXEIRA, S; CAMPOS, G Reforma sanitária: Itália e Brasil. São Paulo: Hucitec-CEBES, 1988.

FLEURY, S. Seguridade social: um novo patamar civilizatório. In: INSTITUTO LEGISLATIVO BRASILEIRO. Os cidadãos na carta cidadã. Brasília: Senado Federal, 2008.
FLEURY, S; BAHIA, L; AMARANTE, P. Saúde em debate: fundamentos da reforma sanitária. Rio de Janeiro: CEBES, 2008.

FLEURY, S. Construcción de sujetos políticos y ciudadanos. In: FLEURY, S; SUBIRATS, J; BLANCO, I. Respuestas locales a inseguridades globales: innovaciones y cambios en Brasil y España. Barcelona: Fundació CIDOB, 2008.

GALLO, E. Razão e planejamento: reflexões sobre política, estratégia e liberdade. São Paulo: Hucitec, Abrasco, 1995.

GERSCHMAN, S. A democracia inconclusa: um estudo da reforma sanitária brasileira. Rio de Janeiro: Fiocruz, 1995

HELLER, A. Teoría de las necesidades en Marx. Barcelona: Península, 1986.

LOBATO, L. Estrutura e relações de poder. In: FLEURY, S. Projeto Montes Claros: a utopia revisitada. Rio de Janeiro: Abrasco, 2005.

POULANTZAS, N. O estado, o poder e o socialismo. Rio de Janeiro: Graal, 1980.

SANTOS, B. S. Pela mão de Alice: o social e o político na pós-modernidade. Porto: Afrontamento, 1994.

SANTOS, W. G. Cidadania e justiça, Rio de Janeiro: Campus, 1979.

TOURAINE, A. O que é a democracia? Rio de Janeiro: Vozes, 1996. 